\section{Pursuit of relevance in research}

SIR-In your leading article "How to get back from the dead" (Nature 325, 561; 1987), with whose general argument I largely agree, you say, of the reorganized University Grants Committee (UGC) proposed by the Croham Committee, that an "obvious danger is that such a council might shoot off in an eccentric direction, the pursuit of what is fashionably called 'relevance', not excellence, for example".

If by 'relevance' you mean that which the private sector will pay for and/or is commercially attractive, then I fear that you perpetuate one of the most destructive myths ever to infect British universities, namely that the excellent must be irrelevant to commercial and industrial interests and that anything that the universities do in support of those wider interests cannot be excellent in the academic sense. I believe that excellence and relevance often go hand-in-hand and indeed can depend on one another. Thus, in the past five years, the income (in real terms) that this university has received from selffinancing courses and conferences (by definition 'relevant') has increased by 973 per cent; the income from our associated companies (Salford University Business Services Ltd and Salford University Civil Engineering Ltd and very relevant to us at least) has increased by 580 per cent and our income from research council grants by 95 per cent. As during those five years it is generally recognized to have become more difficult to obtain funding from the research councils, I find it difficult to believe that our pursuit of 'relevance' has been at the expense of research 'excellence'.

It has long been accepted, of course, that degree programmes of the kind that this university offers whereby an academic education is combined with professional training are best taught by those with some knowledge of the context in which those skills are to be practised. But closer examination of our accounts for last year will reveal that our departments have spent, in aggregate, $£ 900,000$ from the monies they earned (by definition on 'relevant' work) on their teaching activities and I have just sanctioned the expenditure of $£ 150,000$ by our Teaching Committee from the profits covenanted to us by Salford University Business Services Ltd, in order to support excellence in our teaching activities. Thus, not only is research excellence at this university not incompatible with 'relevance', teaching excellence - at least as measured by access to up-to-date equipment and more favourable staff-student ratios - is becoming dependent on 'relevant' activities too. This, by the way, is one very good reason why the UGC as well as the research councils should continue to support research in the universities because, as we have shown, the profits from the 'relevant' work that stems from our research is increasingly needed to maintain excellence in the teaching activities that are undoubtedly the UGC's concern.

JoHn Ashworth

University of Salford, (Vice-Chancellor)

Salford MS 4WT, UK

\section{Plight of postdocs}

SIR-Dennis Murphy in his letter on the plight of British postdocs (Nature 325 , 478 ; 1987) raises some pertinent points. The sentiments he expresses, however, bear the hallmark of one safe in the knowledge that he has security of tenure. The problem of salary grading and structure for research staff is clearly one that needs to be addressed, but removing the anomalous age-related scheme to replace it with a flat-rate scale is a recipe for disaster. For if the age-related salary structure is to be removed for fixed-term contract staff, ought it not be removed for tenured staff also?

Murphy obviously sees the postdoc position as a vocational one. How else could he believe that a postdoc in his $40 \mathrm{~s}$ would be happy to be employed on the salary of his junior counterpart fresh from a $\mathrm{PhD}$ ? He notes that one of the reasons for the 'brain drain' is "the greater scientific and pecuniary opportunities that exist abroad". Why, therefore, does he assume that a mature postdoc in Britain would be any happier to work for a junior postdoc's salary simply because it's a job?

Postdocs soon discover the difficulties of obtaining mortgages with fixed-term contracts and the prospect of an uncertain nomadic existance does not provide the stability needed to start a family. Unless we are to deny our fixed-term contract staff the same hopes and aspirations held by contemporaries in industry and tenured positions, the removal of the 'safety net' of age-related salaries is not a viable proposition.

\section{Department of Biology,}

A. PARSONS

University of York,

York YO1 5DD, UK

SIR-I wonder whether Denis Murphy (Nature 325, 478; 1986), who writes about postdoctoral salaries, would be so content if it were suggested that the annual increments enjoyed by tenured lecturers should also be abolished, and that all lecturers, of whatever age and experience, should be paid the same salary.

The whole point of the age-related scale is that it is supposed to reflect the usual correlation of age with practical labora- tory experience. The more experienced a postdoctoral worker, the more useful he or she is to a research team. Industry recognizes this, and pays people more when they have more useful experience. In the United States, the 'tenure-track' system allows researchers to progress through at least a semblance of a career structure as they gain age and experience. In Britain, because there is no career structure for scientific researchers, there is no way for highly qualified and experienced personnel to remain in the profession. Highquality researchers will not be persuaded to stay by the prospect of continued shortterm employment at the lowest possible salaries. What we now have is university research 'at the bench' by newly-qualified inexperienced postdocs while a small pool of experienced personnel who have lectureships spend all their time on teaching, administration and the hunt for new grants, and rarely, if ever, do any research. Surely there is a better way than this?

$\quad$ MICHAEL D. BARON
Department of Biochemistry,
University of Leicester,
Adrian Building
University Road,
Leicester LE1 7RH, UK

\section{Confining AIDS}

SIR-There is little doubt that the incidence of AIDS (acquired immune deficiency syndrome) is surpassing all expectations and can only increase still further as it reaches Asia. It has indeed reached India as well as Thailand, where a member of the US Embassy personnel was infected.

Special interest groups, such as homosexual associations, are highly organized in purchasing the influence of legislators whose duty it is to protect the public in general. Civil liberties unions, too, are on the side of the spreader of AIDS.

The decision of the Indian Council for Medical Research (see Nature 324, 294; 1986) to institute blood tests for foreign students is a good beginning in the attempt to limit the spread of AIDS. But the main source of infection must obviously be sought in tourists. A visa should be given only to AIDS-negative applicants in all countries where AIDS is not yet widespread. This would be more easily accomplished in the countries, usually the United States and Europe, where most of the tourists originate and where facilities would permit the no-AIDS certificate to be part of the visa application procedure.

Laboratoire de Physio-Hormono-

M.K. Agarwal

Réceptérologie,

Université Pierre et Marie Curie,

15 Rue de l'École de Médecine,

75270 Paris Cedex 06,

France 